\title{
ANTIPSICÓTICOS DE LONGA AC̣ÃO COMO FACILITADORES DA ADESÃO NO TRATAMENTO DA ESQUIZOFRENIA: RELATO DE CASO
}

\section{LONG-ACTING ANTIPSYCHOTICS AS A FACTOR FOR IMPROVING TREATMENT ADHERENCE IN SCHIZOPHRENIA: CASE REPORT}

\section{Resumo}

Este artigo relata o caso de um paciente jovem em primeiro episódio psicótico e com dificuldade de adesão ao tratamento, no qual foi utilizado um antipsicótico de segunda geração de ação prolongada. Os antipsicóticos de longa ação devem ser considerados mais amplamente no tratamento da esquizofrenia pela facilidade do manejo e segurança na tomada da medicação, pois melhoram a adesão e, consequentemente, o prognóstico dos pacientes.

Palavras-chave: Antipsicóticos, esquizofrenia, adesão ao tratamento.

\section{Abstract}

This article describes the case of a young patient in his first psychotic episode and facing difficulties adhering to treatment, in which second-generation long-acting antipsychotics were used. The use of these drugs should be more often considered in the treatment of schizophrenia, due to their easy handling and safety, as they improve treatment adherence and consequently the prognosis of patients.

Keywords: Antipsychotics, schizophrenia, treatment adherence.

\section{INTRODUÇÃo}

A esquizofrenia é uma doença complexa e multifatorial, com períodos alternados de remissão parcial ou total e recaídas frequentes'. As crises podem ocasionar prejuízos tanto na esfera cognitiva como na afetiva, e até mesmo na vida econômica dos pacientes. A cada recaída, a recuperação pode ser mais lenta e menos completa, as internações tornam-se mais frequentes, a doença pode tornar-se mais resistente ao tratamento, há um risco aumentado de autodano e perda de lar, e é mais difícil recuperar o nível anterior de funcionamento². A baixa adesão aos antipsicóticos é a causa mais comum de recaída ${ }^{3}$. Após um primeiro episódio psicótico, a taxa de descontinuação de medicação durante o primeiro ano de tratamento varia de 26 a 44\%; no estudo Clinical Antipsychotic Trials for Intervention Effec $\neg$ tiveness (CATIE), a taxa de descontinuação chegou a 74\% em 18 meses.

Dentre as estratégias adotadas para melhorar a adesão ao tratamento da esquizofrenia está o uso de antipsicóticos de longa ação ou injetáveis. Seu uso foi iniciado na década de 1960, a princípio em formulações de antipsicóticos de primeira geração e, mais tarde, de segunda geração. Essas medicações precisam ser aplicadas em um intervalo entre 2 e 4 semanas e garantem a tomada de medicação e a manutenção dos níveis séricos.

$\bigcirc$ caso a seguir é de um paciente jovem, em um primeiro episódio psicótico e com muita dificuldade de adesão ao tratamento, e descreve nossa experiência com a prescrição de um antipsicótico de segunda geração de ação prolongada.

\section{RELATO do CAso}

\section{Identificação}

Paciente do sexo masculino, 21 anos, natural e procedente de São Paulo, solteiro, com grau superior incompleto, desempregado (os dados da identificação foram alterados para preservar o anonimato do paciente).

\section{História da doença}

Os pais perceberam que o filho estava confuso, não falava coisas coerentes e estava agressivo com a mãe aos 19 anos. $\bigcirc$ paciente conta que a TV conversava com ele, que barulhos dos vizinhos o incomodavam muito e que passou a ficar persecutório com 


\section{VICTOR SICILIANO SOARES \\ CLAUDIANE SALLES DALTIO \\ CECÍLIA ATTUX}

Programa de Esquizofrenia (PROESQ), Universidade Federal de São Paulo (UNIFESP), São Paulo, SP.

um vizinho. Seu rendimento na faculdade caiu, ele mal conseguia frequentar as aulas, brigou com seus amigos e ficou muito isolado.

A família procurou tratamento com psiquiatra particular, que prescreveu zuclopentixol depósito 1 ampola/mês + sulpirida 50 $\mathrm{mg} / \mathrm{dia}$. Houve melhora dos sintomas positivos com tais medicações, porém o paciente apresentou efeitos colaterais (dificuldade de se locomover e contraturas musculares), que melhoraram com biperideno 2 mg nos 10 dias após o depósito.

Após 8 meses, o paciente teve o primeiro atendimento em nosso serviço. Dizia não compreender bem o que acontecia com ele, tinha dúvidas sobre poder ou não usar drogas (era tabagista [um maço/dia] e ainda fazia uso ocasional de maconha e álcool). Queixava-se de desânimo e sonolência, havia voltado aos estudos mas não conseguia se concentrar nas aulas. "Sinto minha cabeça estranha, como se corpos me invadissem". Foi tentada gradativamente a substituição da medicação por aripiprazol, porém se queixava de cefaleia e teve má adesão.

\section{História de vida}

$\bigcirc$ paciente apresentava desenvolvimento neuropsicomotor adequado e bom rendimento escolar até os 13 anos. Com esta idade, usou maconha pela primeira vez. Chegou a ser expulso de uma escola devido ao uso da substância. Dos 15 aos 17 anos, intensificou o uso da maconha, chegando a três cigarros/dia.

Os sintomas prodrômicos iniciaram entre os 17 e 19 anos. Nesse período, apresentava insônia, dificuldade de concentração (não conseguia manter uma conversa longa e logo se dispersava) e comportamento explosivo com familiares e namorada.

\section{Exame psíquico}

Consciente, normovígil, colaborativo/passivo, pouco contato visual, orientado globalmente no tempo e espaço, apático/ansioso, afeto distanciado, pensamento de curso lentificado, com frouxidão associativa e pseudoalucinação, ausência de sinal indireto alucinatório, memória de evocação prejudicada, não heteroagressivo, pouco lábil em alguns momentos, psicomotricidade pouco diminuída, juízo de realidade e crítica prejudicados. Apresentou escore 6 (gravemente doente) na Escala de Impressão Clínica Global - Gravidade (CGI-S).

\section{Evolução}

O paciente começa a se questionar sobre seu prognóstico: "Vou voltar ao normal? Vou conseguir interagir de novo com as pessoas?". Mantinha sensações corporais estranhas e achava que tinha um dom. Questionava seu diagnóstico de esquizofrenia, considerando que esteve doente somente nos momentos de maior intensidade sintomática e desconsiderando a cronicidade do quadro. Iniciado trabalho de psicoeducação durante as consultas para o paciente e seus pais.

Dois meses depois, estava em uso de aripiprazol 15 mg e começou a reduzir a dose para meio comprimido por conta própria. Dizia estar curado e achava que havia passado por uma fase difícil, porém se mostrava ambivalente com relação ao uso do medicamento.

Nessa época, apresentou melhora da socialização e da capacidade de concentração, entretanto seus pais referiram persecutoriedade com relação ao vizinho: "Ele diz que o vizinho faz barulho só pra incomodá-lo". O aripiprazol foi aumentado para 22,5 mg, e depois para 30 mg, com boa resposta, apesar da manutenção do uso ocasional de maconha.

Após 4 meses, os pais referiram que filho vinha bem, mas ficava muito agressivo e tinha episódios de impulsividade na presença da mãe. Chutava objetos e dava murros nas portas. Mantinha o discurso de que não queria tomar medicações e recusava algumas doses.

Um mês depois, decidiu-se introduzir paliperidona de depósito e suspender o aripiprazol. Foi feito o esquema de inicialização e, em seguida, aplicada a dosagem de 100 mg/mês. Em 2 meses, a dose foi aumentada para 150 mg/mês. Após 1 mês, o paciente referia não estar se sentindo bem, dormia pouco, queixava-se de incômodo, o qual não sabia definir "se é na cabeça ou no corpo". Mantinha persecutoriedade com relação ao vizinho. Foi aventada a hipótese de acatisia, e foi associado clonazepam 2 mg à noite, com resolução da inquietação.

Os pais referiram que o paciente ficava bem nas 2-3 semanas após a injeção, mas na última semana ficava mais agressivo e persecutório. Voltou para a faculdade, mas não conseguia permanecer até o final da aula. Mantinha-se relutante em aceitar a medicação e ambivalente com relação ao diagnóstico e ao tratamento proposto. Referia não fazer uso de maconha há 2 meses, porém aumentou a frequência e a quantidade do uso de álcool. Segundo o pai, o paciente ainda apresentava dificuldade de atenção e concentração.

No mês seguinte, o paciente passou a aceitar melhor as aplicações da medicação. Interrompeu o uso da maconha, mas continuava insistindo que tinha muita vontade de beber. Nessa época, aumentamos a paliperidona para $150 \mathrm{mg} / 3$ semanas. Um mês depois, foi referida diminuição da persecutoriedade, e o paciente começou a apresentar melhora na atenção e concentração, além de conseguir conversar com mais desenvoltura. Negou efeitos co- 


\section{RELATO DE CASO}

\section{VICTOR SICILIANO SOARES \\ CLAUDIANE SALLES DALTIO CECÍLIA ATTUX}

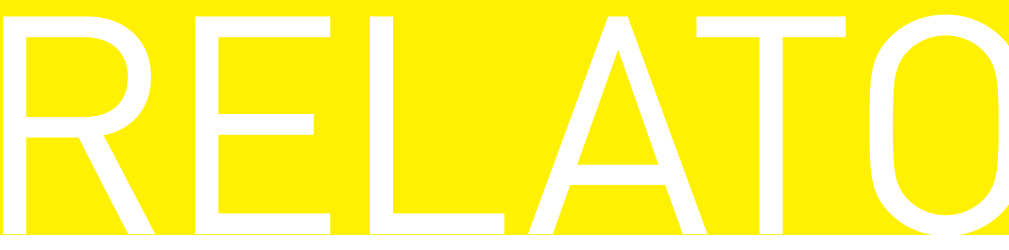

laterais após aumento da dose. Seu novo escore na CGI-S foi 4 (moderadamente doente).

\section{Dıscussão}

Os antipsicóticos de longa ação são tão efetivos quanto os antipsicóticos orais, com a vantagem da formulação injetável, que garante cobertura medicamentosa para os pacientes não aderentes ao tratamento. Apesar disso, esses medicamentos ainda são subutilizados devido a atitudes negativas por parte dos profissionais de saúde e dos pacientes ${ }^{5}$. No Canadá, as maiores taxas de uso são observadas em programas específicos de quadros psicóticos iniciais ${ }^{6}$. No caso em questão, tratava-se de um paciente jovem, ainda com pouco tempo de histórico psicótico e com grande dificuldade de entendimento e aceitação da doença, sendo o uso do antipsicótico de longa ação uma estratégia para garantir a adesão medicamentosa.

Uma coorte naturalística para avaliar a taxa de descontinuação foi realizada em Londres com 210 pacientes em uso de palmitato de paliperidona. ${ }^{7}$ A medicação foi efetiva e bem tolerada, sendo que, ao final do primeiro ano, $80 \%$ dos pacientes continuavam em uso da medicação e somente $5 \%$ haviam descontinuado o tratamento devido aos efeitos adversos. $\bigcirc$ uso correto do esquema de inicialização da medicação e o início do uso em pacientes ambulatoriais foram dois fatores associados positivamente à taxa de adesão. Ambos os fatores foram também observados neste caso.

Em resumo, os antipsicóticos de longa ação devem ser considerados mais amplamente no tratamento da esquizofrenia pela facilidade do manejo e segurança na tomada da medicação, fatores que melhoram a adesão e, consequentemente, o prognóstico dos pacientes.

\section{Correspondência:}

Cecília Attux

Rua Machado Bittencourt, 222

04044-000 - São Paulo, SP

E-mail: cattux@gmail.com

Fontes de financiamento inexistentes.

Conflitos de interesse: Victor Siciliano Soares não tem conflitos a declarar. Claudiane Salles Daltio é investigadora principal e subinvestigadora em estudos clínicos patrocinados pela Janssen-Cilag e Roche; e dá aulas médicas para a Novartis Biociências. Cecília Attux é subinvestigadora em estudos clínicos patrocinados pela Roche.

\section{Referências}

1. Lieberman JA. Is schizophrenia a neurodegenerative disorder? A clinical and neurobiological perspective. Biol Psychiatry. 1999:46:729-39.

2. Weiden PJ, Kozma C, Grogg A, Locklear J. Partial compliance and risk of rehospitalization among California Medicaid patients with schizophrenia. Psychiatr Serv. 2004;55:886-91.

3. Kaplan G Casoy J, Zummo J. Impact of long-acting injectable antipsychotics on medication adherence and clinical, functional, and economic outcomes of schizophrenia. Patient Prefer Adherence. 2013;7:117180.

4. Lieberman JA, Stroup TS, McEvoy JP, Swartz MS, Rosenheck RA, Perkins DO, et al. Effectiveness of antip $\urcorner$ sychotic drugs in patients with chronic schizophrenia. N Engl J Med. 2005;353:1209-23.

5. Waddell L, Taylor M. Attitudes of patients and mental health staff to antipsychotic long-acting injections: systematic review. Br J Psychiatry Suppl. 2009;52:S4350.

6. Manchanda R, Chue P, Malla A, Tibbo P, Roy MA, Williams $\mathrm{R}$, et al. Long-acting injectable antipsychotics: evidence of effectiveness and use. Can J Psychiatry. 2013;58:5S-13S.

7. Attard A, Olofinjana $O$, Cornelius $\vee$, Curtis $\vee$, Taylor D. Paliperidone palmitate long-acting injection-prospective year-long follow-up of use in clinical practice. Acta Psychiatr Scand. 2014:130:46-51. 